\title{
O LUGAR DOS CONHECIMENTOS TRADICIONAIS E A TRANSFERÊNCIA DOS EFEITOS DAS CONTRAÇÕES CÍCLICAS PARA O MEIO AMBIENTE
}

\section{THE PLACE OF TRADITIONAL KNOWLEDGE AND THE TRANSFER OF THE EFFECTS OF CYCLICAL CONTRACTS TO THE ENVIRONMENT}

André R. C. Fontes

Resumo: Os conhecimentos tradicionais, considerados objetivamente, formam domínios de saber numa biorregião, na qual dela se possam extrair específicos conhecimentos sobre a flora e a fauna local. Têm eles um significado marcado por condições econômicas de existência, que podem encontrar na consciência dos homens o reflexo de sua expressão. E suas formas de apreensão brotam de modo prévio e definitivo, e as condições econômicas, sociais e políticas da existência não fazem mais do que depositar ou imprimir-se como um aspecto secundário a esse sujeito para o qual o conhecimento é destinado. O presente artigo tem por objetivo analisar os conhecimentos tradicionais, sua importância e a forma de proteção, mediante normas jurídicas, de tais conhecimentos. Nesse contexto, busca demonstrar o impacto da Constituição da República sobre as comunidades tradicionais, entendendo que as normas constitucionais materializam os fundamentos jurídico-estatais do modo de vida de cada família, de cada comunidade de que seria a sociedade brasileira. Estuda, também, a democratização do sistema político brasileiro e sua influência sobre as comunidades tradicionais, tanto no que se refere ao reconhecimento de direitos, na observância da lei, quanto na participação do povo na atividade jurídica e aplicação do Direito.

Palavras-chave: Direito. Comunidades Tradicionais. Conhecimentos Tradicionais

i Doutor em Direito Civil pela Universidade do Estado do Rio de Janeiro - UERJ (2005), Doutor em Ciências Ambientais e Florestais pela Universidade Federal Rural do Rio de Janeiro - UFRRJ (2015), Professor na Universidade Federal do Estado do Rio de Janeiro - UNI-RIO e Desembargador no Tribunal Regional da $2^{\mathrm{a}}$ Região (Rio de Janeiro e Espírito Santo). 
Abstract: The traditional knowledge, considered objectively, forms domains of knowledge in a bioregion, in which it can extract specific knowledge about the local flora and fauna. They have a meaning marked by economic conditions of existence, which can find in men's consciousness the reflection of their expression. And their forms of apprehension emerge in a prior and definitive way, and the economic, social, and political conditions of existence merely deposit or print themselves as a secondary aspect to that subject for which knowledge is destined. The aim of this article is to analyze traditional knowledge, its importance and the form of protection, through legal norms, of such knowledge. In this context, it seeks to demonstrate the impact of the Constitution of the Republic on traditional communities, understanding that constitutional norms materialize the legal-state foundations of the way of life of each family, of each community of which Brazilian society would be. It also studies the democratization of the Brazilian political system and its influence on traditional communities, both in terms of the recognition of rights, in compliance with the law, and in the participation of the people in legal activity and in the application of Law.

Keywords: Law. Tradicional Communities. Tradicional Knowledge. 


\section{INTRODUÇÃO}

Tomados como valores intrínsecos, os conhecimentos tradicionais não somente devem ser protegidos por seu valor econômico, mas, também, como parte substancial da identidade cultural, da capacidade nacional de diversificar as perspectivas do conhecimento dos seres vivos, para dar equilíbrio às conquistas dos povos, seu titulares de fato, e para manter o status quo ambiental dos locais onde são desenvolvidos, a par do conhecimento e do valor da biodiversidade.

Em prol da superação dos problemas enfrentados pela afirmação dos conhecimentos tradicionais diante das ameaças econômicas, devemos nos ater a duas ordens de ideias relacionadas aos conhecimentos: a de que é um objeto de direito, um bem, portanto, na classe dos imateriais ou intangíveis, dependendo do seu enquadramento jurídico ou econômico; e a de que se trata de um instituto que satisfaz as exigências e expectativas de bem-estar econômico, social, cultural dos povos, que procuram elevar os conhecimentos da biodiversidade e, como consequência, uma causa específica e secundária de proteção do meio ambiente. O ordenamento jurídico só reconhece e protege aquilo que tem algum valor patrimonial ou econômico, e como tal, necessita ser conhecido e delimitado pelos valores da ordem social que, nos conhecimentos tradicionais, se cruzam.

A influência das normas jurídicas sobre o modo de vida das comunidades tradicionais se efetua também ao se empregar os instrumentos jurídicos para combater os elementos mais caducos das relações sociais, além de manter afastada a conduta antissocial de alguns indivíduos. As normas jurídicas delineiam as principais tarefas e objetivos a longo prazo na luta da proteção dos povos tradicionais e a erradicação da causas que possam afetar negativamente esses grupos por meio de métodos, formas e procedimentos mais eficazes e também consentidos pelo Estado para influir em pessoas que se opõem à sociedade, além de criar direitos e deveres de organizações estatais e instituições sociais chamadas para combater os fenômenos antissociais. As normas jurídicas contemplam um sistema diverso de estímulos ao comportamento do ativismo sociojurídico dos cidadãos em se amparar na lei, materializar suas prescrições, prevenir, deter infrações.

Servem, pois, as normas, para fixar e desenvolver o modo de vida das comunidades tradicionais, erradicando as concepções alheias ao 
estilo de vida desses grupos e assegurar que a ordem social proporcione as condições mais favoráveis ao cumprimento das tarefas de edificação das estruturas das comunidades. Elas criam a base técnico-material de proteção, aperfeiçoando os mecanismos sociais e educando o indivíduo membro das comunidades no cumprimento de tarefas de alcance geral para o grupo e para toda a sociedade em geral.

\section{DESENVOLVIMENTO}

O lugar diretor, o marco do sistema jurídico, corresponde ao que ditam as normas constitucionais, ou seja, as prescrições jurídicas formuladas e consignadas na Constituição da República. São as normas constitucionais que materializam os fundamentos jurídico-estatais do modo de vida de cada família, de cada comunidade de que seria a sociedade brasileira. Os fundamentos do regime sociopolítico e econômico, as vinculações mútuas entre o Estado brasileiro e cada indivíduo do País, os princípios orgânicos e objetivos do Estado e de todo povo brasileiro, enfim, os requisitos mínimos que se exigem na conduta de cada brasileiro.

O reconhecimento de um vínculo indissolúvel entre a vida na comunidade tradicional e o desenvolvimento do Brasil, de suas forças criadoras e suas potencialidades é uma obra acima de tudo medular da Constituição da República.

Já nos princípios enumerados no art. $1^{\circ}, \mathrm{V}$, da Constituição da $\operatorname{Re}$ pública encontramos a base da edificação da variedade na formação do povo brasileiro. Toda etapa lógica na construção constitucional do País está assentada na variedade das energias criadoras do regime constitucional e do modo vida do povo brasileiro. A caracterização dos fatores fundamentais econômicos, sociopolíticos e espirituais que determinam o modo de vida do povo brasileiro é também o que permite o desenvolvimento da ciência, da cultura e do bem-estar de todos. São as premissas cada vez mais favoráveis ao desenvolvimento integral do indivíduo que permitem o estabelecimento de relações maduras que marcam todos os níveis sociais, por uma igualdade de direito e de fato de todas as comunidades e manifestações étnicas que compõem a nação brasileira.

A Constituição da República Federativa do Brasil parte do pluralismo, serve ao interesse da construção de uma sociedade livre e assegura o bem-estar a todo o povo, em todo o âmbito da vida social. O ativismo sociopolítico dos brasileiros, como importante corte no modo de vida 
do brasileiro, se materializa não somente porque é o povo que o exerce, mas porque a manifestação do poder popular pode se dar também de formas variadas. Ao proclamar a Constituição a soberania do povo, a Constituição estrutura todo um sistema de instituições jurídicas e estatais que garantem o exercício prático do poder e dos direitos do povo. Além disso, estabelece a Constituição a eleição em todos os órgãos do poder do Estado, de baixo para cima, e introduz instituições democráticas e de normas no sistema representativo, além de contemplar o exercício de formas de democracia direta, como é o caso do referendum.

A democratização do sistema político brasileiro influi diretamente no modo de vida das comunidades tradicionais e assegura, diante de todo o desenvolvimento que o País alcançou, uma maior eficiência sobre essa base dos efeitos diretos das atividades do Estado e do Direito sobre todos os aspectos. As mais variadas formas de participação do povo na atividade jurídica e na aplicação do Direito, tanto devem ser maiores na organização como na ordem da atividade vital de todos os membros da sociedade.

O sistema político do País responde ao próprio fortalecimento do modo de vida de cada brasileiro, promovendo o ativismo social e a cidadania no cumprimento de importantes tarefas do Estado e da sociedade, de realizar indeclinavelmente na prática dos requisitos das normas verdadeiramente democráticas de dito modo de vida. Esse sistema conforma estáveis posições sociopolíticas e jurídicas do indivíduo, cuja atitude faz o poder que se caracteriza pela confiança e ativismo democrático, enquanto que sua atitude faz as decisões jurídicas do poder denotarem um fundo convencimento da necessidade de atacá-las estritamente.

As instituições estatais, as organizações sociais e manifestações espontâneas devem assegurar a ordem jurídica, a proteção dos interesses da sociedade e dos direitos e liberdades de todos. A universalidade do imperativo de observar as leis é algo próprio do modo de vida democrático. Em correspondência com as esferas principais do modo de vida democrático enumeremos, pois, uma aproximação às comunidades tradicionais e a formulação de um conceito que as identifique e discrimine.

No âmbito da cultura e das condições existenciais, a Constituição da República impõe à cidadania o dever de cuidar da natureza e proteger seus espaços.

Em geral, os deveres constitucionais vêm a ser a forma jurídica de expor e fixar os princípios que o Estado exige do indivíduo nas esferas 
fundamentais da sua atividade. A função desses deveres constitucionais radica em assegurar uma disciplina consciente de toda manifestação sociopolítica da cidadania. Disciplinar, e mesmo autodisciplinar e acrescentar graus de responsabilidade cívica aos brasileiros, está ligado indissoluvelmente com o sucessivo fortalecimento e desenvolvimento da vida no País.

Um dos importantes elementos desse modo de vida cívico e plural é o reconhecimento das formas mais espontâneas nas (e em todas) esferas da vida em sociedade. Assentada nessa disciplina consciente de compreensão e diversidade de interesses em um único sistema de normas sociais vigentes é que surge a figura jurídica da comunidade tradicional.

O uso da boa-fé dos direitos e deveres jurídicos, das liberdades e do cumprimento estrito de deveres representa uma propriedade essencial na consciência e atividade vital dos brasileiros, a quem se submetem, cumprem, voluntaria e conscientemente, as prescrições jurídicas e participam, com dinamismo próprio, da proteção de seus próprios interesses.

Para melhor compreender o termo comunidade tradicional, toda a complexidade e diversidade que lhes são inerentes, deve ser realizada a tarefa mais difícil: estar reduzida a locução a uma figura, a um único conceito.

A determinação de um conceito ao se iniciar uma aproximação com o termo comunidade tradicional é a única maneira de tornar possível, com máxima exatidão, todo estudo que permita tomar em consideração a figura da comunidade tradicional.

Para uma perspectiva mais ampla, e valendo-se de conhecidas similitudes dos contextos sociais, econômicos, culturais, religiosos, políticos e legais que circundam essas comunidades, pode-se computar, conforme a variação de geográfica, pobreza ou simples exclusão social, diferenças marcantes entre elas.

É com esse fim agregador que se aproveitam as possibilidades de ampliação de estudos intracomunidades e das dependências empíricas que a falta de identidade entre uma e outra possa gerar ao se qualificar pessoas, locais e culturas. O mais difícil talvez seja determinar os elementos conceituais diante de números que apresentar dados mais quantitativos que a inclusão do que seria comum ou do que seria reduzido a alguns grupos. Nesse caso, traçar linhas substanciais na estrutura de grupos tão heterogêneos parece gerar a impossibilidade de uma consideração absoluta da totalidade. 
Para se determinar o número de comunidades que fixam elementos conceituais em cada ambiente e o tipo de cultura produzida, em dependência às características como tais reconhecidas por serem realmente do grupo, as funções dos estudiosos e dos dados disponíveis seguem os critérios de diferentes línguas, religiões, culturas, organizações políticas sociais e jurídicas.

Quando se constata a particularidade de cada grupo, medem-se também os distintos graus com a sociedade moderna, especialmente a urbana, especialmente nos diferentes níveis de assimilação de padrões culturais forâneos. É necessário notar que são também considerados a maior ou menor aceitação das estruturas jurídicas e sociais formais existentes, além da divisão entre o artesanato ou seu conhecimento do meio ambiente, especialmente das plantas medicinais e sua aplicação.

Uma vez revelada a primeira caracterização destinada a traçar as semelhanças, outra, contraditória, se faz necessária, que é relativa à distinção entre os grupos a partir deles próprios, como seria o caso de ser uma comunidade indígena, remanescente de quilombos ou caiçara. Parte-se nesse caso da especificidade cultural da população que as compõem.

Essa necessidade de determinação cultural permite que a diversidade cultural possa ser aferida tanto entre comunidades culturalmente idênticas como de comunidades culturalmente distintas. Seria o caso de duas comunidades indígenas vistas entre si e entre elas e as comunidades caiçaras, por exemplo.

Computar os tipos torna-se mais adequado ao Brasil que hospeda tipos culturais antitéticos em um mesmo ambiente: indígena, quilombola e caiçara. A despeito de serem tratados como grupos reduzidos individualmente e terem culturas diferenciadas, são um importante componente da identidade nacional do Brasil.

Dessa forma, antes mesmo de se identificar o que é uma comunidade tradicional, uma precisão terminológica se faz necessária, para que o termo comunidade seja rejeitado por outro mais necessário ou aceito, como seria o de nação para as comunidades indígenas destacadas.

Em função de tarefas concretas, a Organização Mundial da Propriedade Intelectual (OMPI), assim como outros organismos internacionais, utilizam os termos "comunidade", "povo" e "população" de forma sinônima para grupos indígenas, a despeito das diferenças semânticas e de significado, razão pela qual não deveriam ser tomados com um só significado. Os termos "povo" e "população" derivam de distintas conotações 
e sua utilização está submetida a consequências políticas e jurídicas no âmbito do Direito nacional de cada país e, igualmente, no Direito Internacional. O termo comunidade, a despeito de sua ampla utilização nos mais variados segmentos sociais, parece ter sido o mais aceito.

Para se sistematizar e elaborar um conceito único de comunidade, deve-se levar em consideração que é o termo contraposto ordinariamente à noção de sociedade. No geral, a ideia de comunidade está associada a um conjunto de indivíduos que convivem em um mesmo ambiente físico e tecnológico, formando um grupo reconhecido, unido por vínculos culturais, linguísticos, religiosos, econômicos e de interesse comum.

A necessidade de apreciar a locução comunidade tradicional nos leva a satisfazer a necessidade de destacar comunidade de comunidade tradicional. Essa espécie de comunidade, a comunidade tradicional, pode ser entendida como grupo de pessoas que mantêm sistemas particulares e contínuos entre os membros da coletividade, se identificam de forma diferenciada e se apresentam com uma identidade que não se confunde com a que eles se apresentam, com características culturais seletivamente reafirmadas e melhoradas.

Junto à especificação do termo comunidade tradicional, outros fatores intervêm em uma nova classificação. Dessa forma, comunidade tradicional e comunidade indígena não são sinônimos, como também não o são comunidade tradicional e comunidade caiçara ou quilombola.

Devido à necessidade de agrupar os diversos tipos de comunidades, deve-se adotar o termo comunidade tradicional de forma mais genérica e deixar que os demais sejam especificações do mais amplo. É por isso que toda comunidade indígena seria uma comunidade tradicional, mas nem toda comunidade tradicional seria uma comunidade indígena. Há comunidades tradicionais não indígenas, já que outras como as caiçaras ou quilombolas poderiam integrar o grupo mais genérico.

\section{CONCLUSÕES}

Por meio da caracterização dos conhecimentos tradicionais, seu uso indevido pela falta de medidas destinadas à sua proteção será a tônica que imperará nesta matéria, na qual pode gerar prejuízos culturais, econômicos, sociais e ambientais. O grau de incorporação de comunidades classificadas como sendo tradicionais não é um problema tecnicamente jurídico ou político. A despeito da Constituição da República destacar as 
comunidades indígenas e quilombolas, o enquadramento dessas figuras parece estar longe de uma rigidez constitucional ou legal de classificação ou enquadramento.

Essa apreciação, a despeito do caráter complementar da lei ou Constituição da República deve, provavelmente, ser resultado de uma apreciação de cunho antropológico ou, de forma combinada antropológico-jurídico. A existência de leis específicas para alguns povos em uma dada ordem jurídica não deve impedir ainda assim o recurso da pesquisa e análise antropológica na constatação da comunidade.

\section{OBRAS CONSULTADAS}

ANTUNES, Paulo de Bessa. Diversidade biológica e conhecimento tradicional associado. Rio de Janeiro: Lúmen Júris, 2002.

BALLETTI, Franca. Sapere tecnico sapere locale. Florença: Alinea, 2007.

BARROS, Benedita da Silva et al. Proteção aos conhecimentos das sociedades tradicionais. Belém: Museu Emilio Goeldi, 2007.

BECHER, Tony. Tribus y territórios acadêmicos. Trad. Andrea Menegotto. Barcelona: Gedisa, 2001.

BELLO, Angela Ales. Culturas e religiões. 2. ed.Trad. de Antonio Angonese. São Paulo: EDUSC, 1998.

BETANCOURT POSADA, Alberto; CRUZ MARÍN, José Efraín. Del saber indígena al saber transnacional. México: UNAM, 2009.

CORREA, Carlos M. Nuevas tendências sobre patentes de invencion em América Latina. Revista del Derecho Industrial, Buenos Aires, n. 39, p. 417-457, set./dez. 1991.

DONATO, Luz Marina et al. Mujeres indígenas, territorialidad y biodiversidad en el contexto latinoamericano. Bogotá: Universidad Nacional de Colombia, 2007.

ESTEBAN PÉREZ, Miguel. Manual de los derechos intelectuales en la República Dominicana. São Domingos: Trajano Potentini ,2005. 
FAUSTO NETO, Antonio et al. Anais do Encontro nacional de unidades de assessoria e transferência de conhecimentos tecnológicos e sociais. Rio de Janeiro: Universidade Federal do Rio de Janeiro, 1995.

FERRAZ, Maria Cristina Comunian Ferraz; BASSO, Heitor Cury. Propriedade intelectual e conhecimento tradicional. São Carlos: UFSCAR, 2011.

FERRETI, Degmar Aparecida. La protección jurídica de los conocimientos tradicionales. Curitiba: Juruá, 2013.

FODELLA, Gianni. Diffusione della tecnologia e organizzazione nello sviluppo econômico. Milão: Giuffrè, 1988.

GARCIA BACCA, Juan David. Historia filosófica de la ciência. México: Unam, 1963.

GONZÁLEZ GRANDIÓN, Ximena Andrea. Legitimación de conocimientos tradicionales. Saarbrücken: Editorial Académica Española, 2011.

GRENIER, Louise. Conocimiento indígena. Trad. Oscar Chavarría Aguilar. Cartago: Editorial Tecnológica de Costa Rica, 1999.

HANNIGAN, John. Sociologia ambiental. Trad. Annahid Burnett. Petrópolis: Vozes, 2009.

IACOMINI, Vanessa. Biodireito e o combate à biopirataria. Curitiba: Juruá, 2009.

KOSZUOSKI, Adriana, Conhecimentos tradicionais. Cuiaba: Carlini \& Caniato, 2006.

LAYTON, Robert. Teorie antropologiche. Trad. Stefano Montes. Milão: II Saggiatore, 2001.

LITTLE, Paul E. Conhecimentos tradicionais para o século XXI Etnografias da intercientificidade. São Paulo: Annablume, 2010.

LUSTOSA, João Augusto. O papel do sistema de patentes na transferência de tecnologia aos países em desenvolvimento. Rio de Janeiro: Forense-Universitária, 1979. 
MASSENO, Manuel David. Apontamentos sobre a Constituição Agrária Portuguesa. In: Perspectivas Constitucionais nos 20 anos da Constituição de 1976. v. i. Coimbra: Coimbra, 1996.

MIRANDA ROSA, F.A.. Sociologia do direito. 6. ed. Rio de Janeiro: Zahar, 1978.

MORAN, Emilio F. OSTROM, Elinor. Ecossistemas florestais. São Paulo: Edusp, 2009.

MOREIRA, Eliane. Conhecimento tradicional e a proteção. Revista T\&C Amazônia, n. 11, p. 33-41, jun. 2007.

MORGENBESSER, Sidney. Filosofia da ciência. Trad. Leônidas Hegenberg e Octany Silveira da Mota. São Paulo: Cultrix, 1972.

PLATIAU, Ana Flávia Barros. VARELLA, Marcelo Dias. Diversidade biológica e conhecimentos tradicionais. Belo Horizonte: Del Rey, 2004.

PUNTEL, Lorenz B. Estrutura e ser. Trad. de Nélio Schneider. São Leopoldo: Unisinos, 2006.

RAMOS, Arthur. As culturas européias e europeizadas. Rio de Janeiro: CEB, 1975.

RIOS, Montserrat; DE LA CRUZ, Rodrigo. MORA, Arturo. Conociminto tradicional y plantas útiles del Ecuador. Quito: Abya-Yala, 2008.

GONZÁLEZ GRANDIÓN, Ximena Andrea. Legitimación de conocimientos tradicionales. Saarbrücken: Editorial Académica Española, 2011.

ROMEO CASABONA, Carlos Maria. Biotecnología y derecho. Bilbao: Comares, 1998.

RUSSELL, Bertrand. El conocimiento humano. Trad. Antonio Tovar. Madri: Taurus, 1959.

SANCHEZ, Enrique. ROLDAN, Roque. SANCHEZ, Maria Fernanda. Derechos e identidad. Bogotá: Disloque, 1993. 
SÁNCHEZ MUÑOZ, María Paloma. La dependencia tecnologica española: contratos de transferencia de tecnología entre España y el exterior. Madri: Ministerio de Economia y Hacienda, 1984.

SCHOLZE, Simone Henriqueta Cossetin. Propriedade intelectual e biotecnología: aspectos jurídicos e éticos. Notícia do direito brasileiro, n. 5, p. 91-115, 1. sem. 1998.

SILVA, José Robson. Paradigma biocêntrico: do patrimônio privado ao patrimônio ambiental. Rio de Janeiro: Renovar, 2002.

SOUZA, Allan Rocha de. Direitos culturais no Brasil. Rio de Janeiro: Azougue, 2013.

TOBON, Natalia. Los conocimientos tradicionales como propiedad intelectual en la Comunidad Andina. Derechos intelectuales. Buenos Aires: Astrea, 2003. p. 135-151.

VINATEA MEDINA, Ricardo G. Propuestas para la protección jurídica de los conocimientos tradicionales en el marco del tratado de libre comércio Perú-EE.UU. Lima: Edição do autor, 2008.

WANDSCHEER, Clarissa Bueno. Patentes \& conhecimento tradicional. Curitiba: Juruá, 2009.

ZANIRATO, Silvia Helena. RIBEIRO, Wagner Costa. Conhecimento tradicional epropriedade intelectual das organizações multilaterais. Revista Ambiente \& Sociedade, v. 10, n. 1, p. 39-45, jan./nov. 2007. 